Int. J. Electrochem. Sci., 14 (2019) 9785 - 9795

International Journal of

ELECTROCHEMICAL

SCIENCE

www.electrochemsci.org

\title{
A Simple, Low-Cost and Efficient $\beta$-CD/MWCNTs/CP-based Electrochemical Sensor for the Rapid and Sensitive Detection of Methyl Parathion
}

\author{
Runqiang Liu ${ }^{1,2,3}$, Yashuang Wang ${ }^{3}$, Dongdong $\mathrm{Li}^{3}$, Li Dong ${ }^{3}$, Bo $\mathrm{Li}^{3}$, Binbin Liu ${ }^{3}$, \\ Huina Ma ${ }^{3}$, Fang Li $^{3}$, Xinming Yin ${ }^{1, *}$, Xiling Chen ${ }^{3, *}$ \\ ${ }^{1}$ College of Plant Protections, Henan Agricultural University, Zhengzhou 450002, China \\ ${ }^{2}$ Postdoctoral Research Base, Henan Institute of Science and Technology, Xinxiang 453003, China \\ ${ }^{3}$ School of Resources and Environment, Henan Institute of Science and Technology, Xinxiang \\ 453003, China \\ *E-mail: xmyin11@163.com ; chenxiling@ hist.edu.cn
}

doi: $10.20964 / 2019.10 .28$

Received: 5 June 2019 / Accepted: 2 August 2019 / Published: 30 August 2019

Based on the $\beta$-cyclodextrin/multi-walled carbon nanotubes/carbon paper ( $\beta$-CD/MWCNTs/CP) composite, a simple, low-cost and efficient electrochemical sensor is first designed in the work for the rapid and sensitive detection of methyl parathion (MP). The characteristic peaks of $\beta$-CD and MWCNTs are simultaneously observed in the XRD and FTIR results, and these two materials disperse homogeneously on the surface of $\mathrm{CP}$ electrode. The results of electrochemical measurements suggest that the obtained $\beta$-CD/MWCNTs/CP composite electrode exhibits remarkable synergetic effect, significantly enhancing the efficiency and sensitivity of electrochemical sensor for the selective adsorption property of $\beta-C D$, high electrical conductivity and large surface area of MWCNTs, as well as easy operation of $\mathrm{CP}$ electrode. Under the optimal conditions, the $\beta$-CD/MWCNTs/CP-based electrochemical sensor exhibits excellent MP determination performance with a low detection limit of $2.4 \mathrm{ng} \mathrm{mL} \mathrm{m}^{-1}(\mathrm{~S} / \mathrm{N}=3)$ and a wide linear concentration range from 0.01 to $13 \mu \mathrm{g} \mathrm{mL}^{-1}$. Given that the $\mathrm{CP}$ is not expensive and the construction of CP-based electrochemical sensor can avoid several complex working procedures, this work has a great significance on promoting the more practical electrochemical sensor for the rapid and sensitive detection of MP.

Keywords: $\beta$-CD/MWCNTs/CP composite electrode; Synergetic effect; Electrochemical sensor; Methyl parathion

\section{$\underline{\text { FULL TEXT }}$}

(C) 2019 The Authors. Published by ESG (www.electrochemsci.org). This article is an open access article distributed under the terms and conditions of the Creative Commons Attribution license (http://creativecommons.org/licenses/by/4.0/). 
